
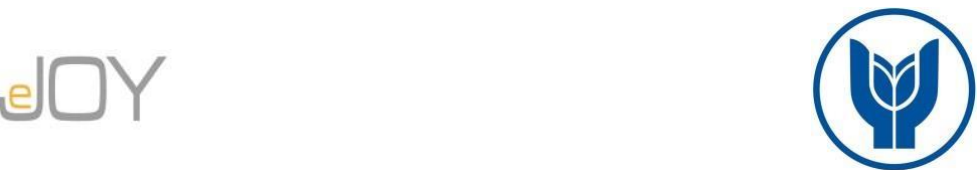

Yürük, B., Acaroğlu, H. / Journal of Yasar University, 2021, 16/61, 1301-1317

\title{
Türkiye'de Eğitim Harcamaları ve Ekonomik Büyüme Arasındaki İlişkinin Doğrusal Olmayan Analizi ${ }^{1}$
}

\section{A Non-Linear Analysis of the Relationship Between Education Expenditures and Economic Growth in Turkey}

\author{
Burcu YÜRÜK, Uşak Üniversitesi, Türkiye, burcu.yuruk@usak.edu.tr \\ Orcid No: 0000-0001-6922-6161
}

Hakan ACAROĞLU, Eskişehir Osmangazi Üniversitesi, Türkiye, hacaroglu@ogu.edu.tr

Orcid No: 0000-0001-6757-2140

Öz: Kamu harcamaları ile ekonomik büyüme arasındaki ilişkiye yönelik literatür incelendiğinde, Wagner yasası ve Keynes hipotezi olmak üzere iki farklı görüs karşımıza çıkmaktadır. Literatürde kamu harcamaları ve ekonomik büyümeye ilişkin iki farkl tartışma olması nedeniyle, kamu harcamalarının ekonomik büyüme için politika aracı olarak kullanılıp kullanılmayacağına yönelik tartışmalar uzun ylllardır devam etmektedir. Bu çalışmada, Türkiye'de eğitim harcamalart ve ekonomik büyüme arasindaki ilişsi, 1980-2015 dönemi zaman serisi verileri kullanılarak Keynes hipotezi çerçevesinde analiz edilmektedir. Çalışma kapsamında, kamu harcamaları içerisinde önemli bir payl olan eğitim harcamalarının ekonomik büyüme üzerindeki etkisinin belirlenmesinin politika yapıcılar için önemli olduğu düşünülmektedir. Çallşmanın ampirik kısmında, asimetrik etkilerin dikkate alındı̆̆g Nonlinear Autoregressive Distributed Lags (NARDL) modelinden yararlanılmaktadır. Bu çalışmada, asimetrik bir eş-bütünleşme yönteminin tercih edilmesi pozitif ve negatif şokların ayrıştırılarak gizli eş-bütünleşme sorunun ortaya çıkarılması açısından önem taşımaktadır. Analiz bulgularına göre; eğitim harcamalarındaki pozitif şokların hem kisa hem de uzun dönemde ekonomik büyüme lehine ve negatif şoklarin ise sadece klsa dönemde ekonomik büyüme aleyhine sonuçlar sergilediği görülmektedir. Elde edilen bulgular, eğitimin pozitif dı̧̧sallığını destekler niteliktedir.

Anahtar Kelimeler: Eğitim Harcamaları, Ekonomik Büyüme, Keynes Hipotezi, NARDL

JEL Sinıflandırması: C22, H52, O40

\begin{abstract}
When the literature on the relationship between public expenditures and economic growth is examined, two different thoughts appear, namely the Wagner law and the Keynes hypothesis. Since there are two different arguments on public expenditures and economic growth in the literature, discussions about whether public expenditures can be used as a policy tool for economic growth, or not, have been going on for many years. In this paper, the relationship between education expenditures and economic growth in Turkey, are analyzed in the framework of Keynes hypothesis by using time series data for the period of 1980-2015. Within the scope of the paper, determining the effect of education expenditures, which has an important share in public expenditures, on economic growth is considered to be important for policy makers. In the empirical part of the paper, the Nonlinear Autoregressive Distributed Lags (NARDL) model, in which asymmetric effects are taken into account, is utilized. In this paper, choosing an asymmetric cointegration method is important in terms of revealing the hidden cointegration problem by decomposing positive and negative shocks. According to the analysis findings, positive shocks in education expenditures present results in favor of economic growth in both the short and long run and negative shocks, on the other hand, present results against economic growth only in the short run. The obtained findings support the positive externality of education.
\end{abstract}

Keywords: Education Expenditure, Economic Growth, Keynes Hypothesis, NARDL

JEL Classification: C22, H52, O40

\footnotetext{
${ }^{1} \mathrm{Bu}$ çalışma, 26.04.2019 tarihinde "V. European Congress on Economic Issues" Kongresinde özet metin olarak sunulan yayınlanmamıș bildirinin geliştirilmiş ve genişletilmiş halidir.
} 


\section{Giriş}

Kamu harcamaları, devletin toplum ihtiyaçlarını karşılamak için yaptığı harcamalar olarak tanımlanmaktadır. Kamu harcamalarının tarihsel süreç içerisinde hem gelişmiş hem de gelişmekte olan ülkelerde sürekli artış sergilediği görülmektedir (Oktayer 2011, 265). Bu artış eğiliminin nedenleri ve kamu harcamalarının ekonomik büyüme için politika aracı olarak kullanılıp kullanılmayacağı iktisadi ekoller içerisinde farklı şekillerde yorumlanmaktadır. Klasik okulun devletin ekonomiye müdahale etmemesi gerektiği düşüncesinden hareketle, Alman iktisatçı Adolph Wagner tarafından ileri sürülen kamu harcamalarındaki artış kanununda, kamu harcamalarındaki artışa ekonomik gelişmelerin neden olduğu ve artış eğiliminin süreklilik kazandığı ifade edilmektedir. Wagner, kamu büyüklüğünün toplumun refah düzeyi arttıkça artış göstereceğini fakat bu artışın süreklilik kazanarak ekonomik büyüme aleyhine bir sonuç yaratacağını ileri sürmektedir (Sarı 2003, 26-27). Diğer bir görüşte ise, devletin ekonomiye müdahalesinin gerekli olduğunu düşünen Keynes, kamu harcamalarının ekonomik büyümeyi olumlu etkilediğini ileri sürmekte ve bu görüş, alan yazınında Keynes Hipotezi olarak yer almaktadır. Keynes'e göre kamu harcamaları, kısa dönem dalgalanmalarını azaltmada dişsal bir politika aracı olarak ekonomik büyümeyi olumlu yönde etkilemektedir (Pınar 2006, 45). Bu iki birbirine zıt görüşte, kamu harcamaları ve ekonomik büyüme arasındaki nedenselliğin yönü de değişmektedir. Kamu harcamalarının dışsal bir politika aracı olarak kullanılabileceğini ileri süren Keynes hipotezinde, nedenselliğin yönü kamu harcamalarından ekonomik büyümeye doğru iken, kamu harcamalarını içsel bir faktör olarak değerlendiren Wagner yasasında ise, ekonomik büyümeden kamu harcamalarına doğru bir nedensellik söz konusudur (Bird 1971, 2; Afzal \& Abbas 2010, 12). Literatürde yer alan söz konusu farklı iki görüş ile kamu harcamalarının ekonomik büyümeyle olan ilişkisi uzun yıllardır tartışılan ekonomi politikası konuları arasında yer almaktadır.

Devletin sunmuş olduğu eğitim hizmeti için yapmış olduğu harcamalar olarak tanımlanan eğitim harcamaları, kamu harcamaları alt kalemleri arasında önemli paya sahiptir. Ülkelerin kalkınma süreçlerinde kilit rol oynayan eğitimin ve bu alanda yapılan harcamaların ekonomik büyüme üzerindeki etkisinin araştırılması, politika aracı olarak değerlendirilip değerlendirilmeyeceği perspektifinden önem taşımaktadır. Ekonomik büyümeye ve gelirin yeniden dağılımına katkı sağlayan eğitim hizmeti, nicelik ve nitelik yönünden belirli bir düzeyde sunulduğunda, emek faktörünün verimliliğinin artmasına olanak sağlamaktadır. Ayrıca, emeğin verimlilik artışına bağlı olarak üretim ve dolayısıyla mili gelir de artmaktadır. Milli gelirde yaşanan artışla ortaya çıkan fırsat eşitliği, gelirin adil bir şekilde dağılımına imkân sağlamaktadır (Arabacı 2011, 102). Literatürde eğitim ve ekonomik büyüme arasındaki ilişki, 
farklı açılardan araştırmalara konu olmaktadır. Eğitimin ekonomik kalkınmadaki önemi, Schultz (1961; 1967), Denison (1962; 1985), Becker (1964) ve Harbison (1971) tarafindan yapılan çalışmalarda ileri sürülmektedir. Solow (1956) tarafından ekonomik büyümenin temellerinin ifade edilmesinin ardından, Mankiw, Romer ve Weil (1992) eğitimin beşerî sermaye yönüyle ekonomik büyüme üzerinde önemli bir rolü olduğunu ileri sürmektedir. Eğitim, beşerî sermaye faktörü olarak içsel büyüme teorilerinde de büyüme literatürüne eklenmiştir. Eğitimin büyümeyle olan yakın ilişkisi, bu alana yapılacak olan harcamaların da ekonomik büyümeyi nasıl etkilediği sorusunu akla getirmektedir.

Literatürde eğitim harcamaları ve ekonomik büyüme arasındaki ilişkiyi açıklamaya yönelik ulusal ve uluslararası düzeyde birçok teorik ve ampirik çalışma mevcuttur. Söz konusu ampirik çalışmalarda, seçilen ekonometrik yöntemlerde doğrusal analizlere odaklanıldığını söylemek mümkündür. Doğrusal analizlerde, negatif ve pozitif şokların etkilerinin homojen olduğu kabul edilmektedir. Pozitif ve negatif şokların aynı olmadığı ve saklı eş-bütünleşmeye neden olduğu ilk kez Granger ve Yoon (2002) tarafından ileri sürülmüştür. Granger ve Yoon (2002)'a göre, doğrusal yöntemler değişkenler arasındaki saklı eş-bütünleşmeyi açıklamakta yetersiz kalmaktadır. Bu çalışmada, Türkiye ekonomisinde eğitim harcamaları ve ekonomik büyüme arasındaki saklı eş-bütünleşmeyi ortaya çıkarmak amacıyla asimetrik ilişkileri dikkate alan eşbütünleşme analizi tercih edilmektedir. Bu amaç doğrultusunda, Türkiye'de 1980-2015 dönemi zaman serisi verileri kullanılarak eğitim harcamalarının ekonomik büyüme üzerindeki etkisini Keynes hipotezi çerçevesinde analiz etmek için NARDL modelinden yararlanılmaktadır. Shin, Yu ve Greenwood-Nimmo (2014) tarafından geliştirilen NARDL modeli, kısa ve uzun dönem katsayılarını aynı anda test etme olanağı sunmaktadır. Bu çalışmanın, değişkenlerde meydana gelen pozitif ve negatif şokların yönü ve şiddetinin belirlenmesi ve heterojen yapıdaki değişenlerin ayrıştırılması açısından literatüre önemli bir katkı sağlayacağı düşünülmektedir. İki bölümden oluşan bu çalışmada, birinci bölümde ekonomik büyüme ve eğitim harcamaları arasındaki ilişkinin teorik çerçevesi alan yazınındaki çalışmalar özetlenerek incelenmektedir. İkinci bölümde ise, asimetrik etkilerin dikkate alındığı NARDL modeli ile elde edilen eğitim harcamalarına ait pozitif ve negatif şokların, ekonomik büyüme üzerindeki etkisi ampirik bulgular çerçevesinde açıklanmaktadır.

\section{Eğitim Harcamaları ve Ekonomik Büyüme İlişkisi}

Eğitimin ekonomik büyümeyi önemli düzeyde etkilediğine dair ilk görüşler, Adam Smith, Alfred Marshall, Irving Fisher ve Thomas Malthus gibi klasik iktisatçılar tarafindan vurgulanmıştır. Solow (1956) tarafından ekonomik büyüme modelinin geliştirilmesinin 
ardından, izleyen yıllarda Schultz (1961) ve Mincer (1973)'in yapmış olduğu çalışmalarda da ekonomik büyümenin yalnızca fiziksel sermayeye bağlı olmadığı, beşeri sermayenin yükseköğretime mensup işgücü ile fiziki sermaye getirisini daha fazla artırarak ekonomik büyümeyi etkilediği ileri sürülmektedir (Schultz 1967, 158). Denison (1962)'de ve Denison (1985)' de Cobb-Douglas üretim fonksiyonunda yer alan emek ve sermaye dışında eğitimin de artık bir faktör olarak ABD büyümesini önemli ölçüde etkilediğini ampirik sonuçlara dayanarak ifade etmektedir. Benzer şekilde, Harbison (1971) tarafından yapılan çalışmalarda da eğitimin ekonomik büyüme için önemli bir etken olduğu ileri sürülmektedir. Psacharopoulos (1973), ülkelerin gelişmişlik farklılıklarını dikkate alarak yaptığı çalışmada, ülkelerin gelişmişlik düzeylerinin artmasıyla eğitimin getirisinin azaldığı sonucuna ulaşmakta ve bu sonucu azalan verimler yasası ile açıklamaktadır (Psacharopoulos 1994, 1326-1328). Barro (1991) ise, yaptığ1 çalışmada, eğitim seviyesindeki artışın istihdam ve yatırım harcamalarındaki artıştan daha fazla ekonomik büyümeyi etkilediği ifade etmekte ve bu sonuç Musila ve Bellasi’nın (2004) yaptığı çalışma ile benzerlik göstermektedir.

Eğitim, klasik ve neo-klasik büyüme teorilerindeki eksikliklere karşı ortaya atılan içsel büyüme teorilerinde de beşerî sermaye faktörü ile özdeşleşmektedir. İçsel büyüme teorileri temsilcilerinden Romer, marjinal verimliliği yüksek olan bilgiyi, yarattığg dışsallıklar nedeniyle üretim fonksiyonunda uzun vadeli büyümenin koşulu olduğunu ileri sürmektedir (Romer 1986, 1002). Lucas, beşeri sermayeyi merkezine alan 3 farklı model geliştirmiştir. Bunlardan ilki fiziksel sermaye birikimi ve teknolojik değişim, ikincisi yaparak öğrenme ile özel beşeri sermaye birikimi ve üçüncüsü okullaşma ile beşeri sermaye birikimidir. Lucas'ın geliştirdiği modellerde beşerî sermaye ön planda olsa da fiziksel sermaye artışının büyümeye katkısı göz ard1 edilmemektedir (Lucas 1998, 3). Rebelo, diğer içsel büyüme teorilerinde olduğu gibi beşerî sermayenin önemine vurgu yaparak, beşerî sermayenin hızlı büyüme için gerekli olduğuna dikkat çekmektedir (Rebelo 1991, 502-520). Eğitim hizmeti, devletin kamu harcamaları ile toplumun ortak ihtiyaçlarını karşılamak için sunduğu kamu hizmetleri içerisinde yer almaktadır. Eğitim hizmeti, bölünebilirlik ve pazarlanabilirlik açısından özel mal durumunda iken, yarattığı pozitif dışsallık etkisi ile yarı kamusal mal olarak karşımıza çıkmaktadır (Devrim ve Tosuner 1987, 87). Yarı kamusal mal olarak eğitim, piyasa tarafindan üretildiğinde, yaratığı bireysel fayda ile birlikte toplumsal fayda, piyasa tarafından üretilemediğinde ise, bireysel zarar yanında toplumsal zarar da ortaya çıkaracağı için, bu hizmetin devlet tarafindan sunulması gerekmektedir (Edizdoğan, Çetinkaya ve Gümüş 2012, 27-28). Nitekim Keynesyen görüşte, eğitimin fırsat eşitliği yaratacağı düşüncesinden yola çıkılarak, bunun devletin temel görevlerinden biri olduğu ileri sürülmektedir. Ülkelerin gelişmişlik düzeylerinin eğitime 
yaptıkları harcamalar ile ilişkili olduğunu ifade eden Singer (1964), eğitim harcamalarında artan verimler yasasının geçerliliğine dikkat çekmektedir. Eğitime yapılan yatırımların, diğer alanlardaki yatırımlar açısından fırsat yaratabileceğine vurgu yapmaktadır. İktisat literatüründe ekonomik büyüme ve eğitim harcamaları arasındaki ilişkiye yönelik çok sayıda ampirik çalışma mevcuttur. Literatürdeki söz konusu çalışmalar incelendiğinde, zaman aralıklarına, modelde yer alan değişkenlere, ülke veya ülke gruplarına ve kullanılan analiz yöntemlerine göre farklılık gösterse de genellikle ulaşılan sonuçlar eğitim harcamaları ile ekonomik büyüme ilişkisinin pozitif olduğu yönündedir. Söz konusu çalışmalar aşağıda özetlenmektedir:

Çoban (2004)'ün eğitim harcamaları ve GSYH değişkenlerini kullanarak Vektor Error Correction Model (VECM) ile yaptığı çalışmada, GSYH ile eğitim harcamaları arasında, uzun dönemli pozitif bir ilişki olduğu ileri sürülmektedir. Özsoy (2009) ve Öztürk, Kalaycı ve Korkmaz (2017) tarafindan yapılan Vektor Autoregression (VAR) modeli analizlerinde, eğitim harcamalarının ekonomik büyümeyi olumlu etkilediğine dair benzer sonuçlar elde edilmiştir. Eriçok ve Yılancı (2013), İğdeli (2019) ve Akıncı (2017) tarafından yapılan çalışmalarda Autoregressive Distributed Lag Bounds Test (ARDL Sınır Test)'inden yararlanılmıştır. Söz konusu çalışmalarda, eğitim harcamaları ve ekonomik büyüme arasında uzun dönemli anlamlı bir ilişki olduğu sonucuna ulaşılmıştır. Akçacı (2013) ise, Toda-Yamamoto (1995) nedensellik testi sonuçlarına göre, 1998-2012 döneminde eğitim harcamalarından büyümeye doğru tek yönlü nedensellik olduğunu ifade etmektedir. Afşar (2009), Pamuk ve Bektaş (2014) ve Şimşek (2017) tarafından Türkiye'de eğitime yapılan yatırımlar ile ekonomik büyüme arasındaki ilişkiyi tespit etmek amacıyla Granger (1969) nedensellik analizi yapılmıştır. Analizlerin sonucunda benzer şekilde, Türkiye'deki eğitim harcamaları ile iktisadi büyüme arasında tek yönlü nedensellik ilişkisinin olduğu sonucuna ulaşılmıştır. Mallick \& Dash (2015) tarafından yapılan çalışmada, eşbütünleşme ve Granger (1969) nedensellik testleri sonucunda elde edilen bulgular, Hindistan' da eğitim harcamalarıyla ekonomik büyüme arasında uzun dönemli tek yönlü bir nedensellik ilişkisinin varlığını ortaya koymuştur. Uçan ve Yeşilyurt (2016) ve Hussin, Muhammad, Hussin \& Razak (2012)'nin çalışmalarında, Granger (1969) nedensellik testi sonucunda sırasıyla, Türkiye ve Malezya için ekonomik büyümeyle eğitim harcamaları arasında çift yönlü nedensellik ilişkisinin olduğu bulgusu elde edilmiştir. Karış (2019) tarafından Türkiye' de 2003:Q1-2018:Q2 dönemi için ekonomik büyüme ile eğitim harcamaları arasındaki ilişsiyi tespit etmek amacıyla Eangle-Granger eş-bütünleşme testi ve VECM kullanılarak yapılan çalışma sonucunda ekonomik büyüme ile eğitim harcamaları arasında eşbütünleşme ilişkisinin olduğunu sonucuna ulaşılmıştır. Karataş ve Çankaya (2011) tarafından Engle-Granger eş-bütünleşme testi yardımıyla yapılan çalışmada ise, büyümenin eğitim 
harcamalarından kaynaklanmadığı sonucuna ulaşılmıştır. Kızılkaya ve Koçak (2014), 11 OECD ülkesi (Avusturya, Danimarka, Belçika, Fransa, Hollanda, İtalya, Norveç, İspanya, İsveç, İsviçre ve Türkiye) için eğitim harcamaları ve ekonomik büyüme arasındaki ilişkiyi panel veri analiziyle incelemişlerdir. Analiz sonucunda, kamu eğitim harcamalarının ekonomik büyümeyi olumlu yönde etkilediği saptanmıştır. Yardımcığlu, Gürdal ve Altundemir (2014) çalışmalarında 25 OECD üyesi ülke için, Pedroni ve Kao panel eş-bütünleşme, Pedroni DOLS ve FMOLS ve Canning-Pedroni nedensellik yöntemlerini kullanarak uzun dönem ilişkiyi analiz etmişlerdir. Lamda-Pearson sonuçlarında, eğitim ve ekonomik büyüme arasında uzun dönem çift yönlü nedensellik olduğu sonucuna ulaşmışlardır. Selim, Purtaş ve Uysal (2014) tarafından G-20 ülkelerini ele alarak, eğitim harcamalarıyla ekonomik büyüme arasındaki ilişkiyi Havuzlanmış Ortalama Grup Regresyonu ve uzun dönem ilişkinin varlığı da Pedroni panel eşbütünleşme testiyle analiz edilmiştir. Çalışmanın sonucu, iki değişken arasındaki kısa ve uzun dönem ilişkilerinin anlamlı ve pozitif olduğunu işaret etmiştir. Idrees \& Siddiqi (2013)'ün yedi gelişmiş ülke (İngiltere, Amerika Birleşik Devletleri, Kanada, Almanya, İtalya, Fransa ve Japonya) için Kao ve Pedroni panel eşbütünleşme testlerinin uygulandığı çalışmasında, kamu eğitim harcamalarının ekonomik büyümeye etkisinin, gelişmekte olan ülkelerde gelişmiş ülkelere kıyasla daha fazla olduğu sonucuna ulaşılmıştır.

Ulusal ve uluslararası literatürde, VECM, ARDL, VAR, Pedroni ve Kao panel eşbütünleşme, Pedroni DOLS ve FMOLS, Havuzlanmış Ortalama Grup Regresyonu ve doğrusal nedensellik (Canning-Pedroni nedensellik, Granger (1969) nedensellik ve TodoYamomoto (1995) nedensellik) testlerinin tercih edildiği görülmektedir. Söz konusu yöntemler, literatürde doğrusal analiz yöntemleri içerisinde yer almaktadır. Doğrusal analizlerde elde edilen sonuçlar, pozitif ve negatif şoklar için homojen kabul edilmektedir. Granger \& Yoon (2002)'de, pozitif ve negatif şokların homojen kabul edilmesinin, saklı eş-bütünleşmeye neden olabileceğini ileri sürmektedir. Bu nedenle bu çalışmada, pozitif ve negatif şokların etkilerinin birlikte ele alındığ Asimetrik nedensellik testinin tercih edilmesiyle, değişkenler arasındaki ilişkinin pozitif ve negatif şoklarının ayrıştırılmasının, saklı eş-bütünleşme sorununa çözüm getirerek, çalışmanın ulusal ve uluslararası literatüre önemli bir katkı sağlayacağı düşünülmektedir.

\section{Uygulama}

\subsection{NARDL Modeli ve Veri Seti}

Kısa ve uzun dönem asimetrik ilişkilerin negatif ve pozitif değişimlerinin bağımlı değişken üzerindeki etkisini test etmeye olanak sağlayan NARDL modeli, Shin vd. (2014) tarafından 
geliştirilmiştir. $Y_{t} I(0), Y_{t} I(1)$ ve kesirli olarak eş-bütünleşik olan değişkenlerin ARDL modelinde olduğu gibi aynı modelde yer aldığı bu yaklaşımda, serideki değişkenlerin önceden birim kök taşıyıp taşımadığının araştırılması zorunluluğu bulunmamaktadır. Ancak değişkenlerin de hiçbirinin I(2) olmama zorunluluğu bulunması nedeniyle uygulama öncesinde birim kök testlerinin yapılması ve böylece serinin durağanlığının araştırılmasının faydalı olacağı düşünülmektedir. NARDL modeli, Engle-Granger ve Johansen eş-bütünleşme testleri ile karşılaştırıldığında birçok üstünlüğe sahiptir. Bu üstünlükler şu şekilde sıralanabilmektedir (Shin vd. 2014, 286):

Engle-Granger yöntemindeki içsellik sorununun bu modelde bulunmaması, kısa ve uzun dönem katsayı tahminlerinin eş anlı olarak gerçekleştirilebilmesi.

Serilerde durağanlık düzeylerinin aynı olması kısıtlayıcılığının bulunmaması.

Küçük örneklem testlerinde de büyük örneklemde olduğu gibi güvenilir sonuçlar elde edilmesine imkân vermesi.

Diğer eş-bütünleşme testlerine kıyasla daha fazla aşamadan oluşmasına rağmen OLS ile tahmin edilmesi uygulamanın zorluk derecesini azaltmasıdır.

ARDL modeli şu şekilde ifade edilmektedir:

$$
\begin{aligned}
& \theta(L) Y_{t}=\alpha_{0}+\alpha_{1} \psi_{t}+\beta^{\prime} X_{i t}+u_{t} \\
& \theta(L)=1-\sum_{i=1}^{\infty} \theta L^{i} \text { ve } \beta(L)=\sum_{i=1}^{\infty} \beta_{k} L^{k}
\end{aligned}
$$

(1) numaralı denklemde L gecikme operatörünü ve $\psi_{t}$ vektörü ise deterministik değişkenleri ifade etmektedir. NARDL modelinde eş-bütünleşme regresyonu şu şekilde ifade edilmektedir:

$$
\mathrm{Y}_{\mathrm{t}}=\beta^{+} \mathrm{x}_{\mathrm{t}}^{+}+\beta^{-} \mathrm{x}_{\mathrm{t}}^{-}
$$

Burada $\beta^{+}$ve $\beta^{-}$uzun dönem parametreleridir ve $x_{t}$ kxl vektörü şu şekilde ayrışmaktadır:

$$
\begin{aligned}
& \mathrm{x}_{\mathrm{t}}=\mathrm{x}_{0}+\mathrm{x}_{\mathrm{t}}^{+}+\mathrm{x}_{\mathrm{t}}^{-} \\
& \mathrm{X}_{\mathrm{t}}{ }^{+}=\sum_{j=1}^{m} \Delta x_{t}^{+} L^{k}=\sum_{j=1}^{m} \max \left(\Delta x_{j}^{t}, 0\right) \quad \text { ve } \quad \mathrm{X}_{\mathrm{t}}{ }^{-}=\sum_{j=1}^{m} \Delta x_{t}^{-} L^{k}=\sum_{j=1}^{m} \max \left(\Delta x_{j}^{t}, 0\right)
\end{aligned}
$$

(5) numaralı denklem ARDL modeli ile ilişkilendirildiğinde (AECM) elde edilmektedir:

$$
\begin{aligned}
& \Delta Y_{t}=p Y_{t-1}+\theta^{+} x_{t}^{+}+\theta^{-} x_{t}^{-}+\sum_{j=1}^{p-1} \Delta Y_{j-t}+\sum_{j=1}^{q} \Delta\left(\pi_{j}^{+} \Delta x_{j-t}^{+}+\pi_{j}^{-} \Delta x_{j-t}^{-}\right) \\
& \theta^{+}=-\mathrm{p} \beta^{+} \text {ve } \theta^{-}=-\mathrm{p} \beta^{-}, \pi^{+}=-\beta^{+} \varphi_{i}+\psi_{2 i} \text { ve } \pi^{-}=-\beta^{-} \varphi_{i}+\psi_{2 i}
\end{aligned}
$$

(4) numaralı denklemde “t” zamanı, “j” serinin gecikmesini, “j” ise kümülatif toplamın hangi dönem için alındığını ifade etmektedir.

NARDL modeli tahmin süreci sırasıyla aşağıdaki aşamalardan oluşmaktadır: 
Analizde yer alan serilerin birim kök test sonuçlarında serilerin $\mathrm{I}(0)$ ve $\mathrm{I}(1)$ düzeyinde durağan olduğu, I(2) veya daha yüksek düzeyde durağan olan bir seriye rastlanmadiğ 1 sonucunun tespit edilmesi gerekmektedir.

(5) numaralı denklemle ifade edilen AECM OLS ile tahmin edilmektedir.

Hipotez testlerini sınamak için WALD testi kullanılmaktadır. Bu test sonucunda elde edilen $F_{W}$ test istatistiği, Pesaran, Shin ve Smith (2001) ve Shin vd. (2014) tarafindan modelde kullanılan parametrelerin sayısına göre farklı bir F-dağılımı, alt ve üst kritik değerleri ile karşılaştırılmaktadır. $\mathrm{I}(0)$ ve $\mathrm{I}(1)$ şeklinde düzenlenen alt ve üst kritik değeri sırasıyla: $\mathrm{F}_{\mathrm{p}}{ }^{\mathrm{a}}$ ve $\mathrm{F}_{\mathrm{p}}{ }^{\mathrm{u}}$ şeklinde ifade edilmektedir (Shin vd., 2014, 289). Aşağıdaki hipotezler, eş-bütünleşme ilişkisinin yanı sıra uzun dönemde $\mathrm{y}_{\mathrm{t}}, \mathrm{x}_{\mathrm{t}}^{+}, \mathrm{x}_{\mathrm{t}}^{-}$değişkenlerinin seviyeleri arasında ilişki olup olmadığını araştırmak için test edilmektedir:

$\mathrm{H}_{0}: \mathrm{p}=\theta^{+}=\theta^{-}=0$ (Eş-bütünleşme yoktur.)

$\mathrm{H}_{1}: \mathrm{p} \neq \theta^{+} \neq \theta^{-} \neq 0$ (Eş-bütünleşme vardır.)

Test sonuçları ise şu şekilde değerlendirilmektedir:

$\mathrm{F}_{\mathrm{W}}>\mathrm{F}_{\mathrm{p}}{ }^{\mathrm{u}}$ ise: $\mathrm{H}_{0}$ Reddedilmektedir.

$\mathrm{F}_{\mathrm{p}}{ }^{\mathrm{u}}>\mathrm{F}_{\mathrm{W}}>\mathrm{F}_{\mathrm{p}}{ }^{\mathrm{a}}$ ise: Kararsızlık Bölgesi oluşur.

$\mathrm{F}_{\mathrm{p}}^{\mathrm{a}}>\mathrm{F}_{\mathrm{W}}$ ise: $\mathrm{H}_{0}$ Reddedilmemektedir.

$\mathrm{y}_{\mathrm{t}}, \mathrm{x}_{\mathrm{t}}^{+}, \mathrm{x}_{\mathrm{t}}^{-}$değişkenlerinin uzun dönem $\left(\theta=\theta^{+}=\theta^{-}\right)$ve kısa dönem $\left(\pi^{+}=\pi^{-}\right.$veya $\sum_{\mathrm{i}=0}^{\mathrm{q}} \pi_{\mathrm{i}}^{-}, \sum_{\mathrm{i}=0}^{\mathrm{q}} \pi_{\mathrm{i}}^{+}$) seviyeleri arasında simetri ilişkisini tahmin sürecine geçilmektedir. Simetri

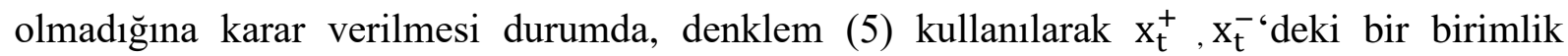
değişmenin yt üzerindeki asimetrik dinamik çarpan etkileri üzerine kurulan hipotezler şu şekilde elde edilmektedir:

$$
\begin{array}{ll}
M_{h}^{+}=\sum_{j=0}^{h} \frac{\delta y_{t-j}}{\delta x_{t}^{+}} & M_{h}^{-}=\sum_{j=0}^{h} \frac{\delta y_{t-j}}{\delta x_{t}^{-}} \\
H_{0}: L_{h}^{+}=\sum_{j=0}^{h} \frac{\delta y_{t-j}}{\delta x_{t}^{+}}=L_{h}^{-}=\sum_{j=0}^{h} \frac{\delta y_{t-j}}{\delta x_{t}^{-}}=0 \\
H_{1}: L_{h}^{+}=\sum_{j=0}^{h} \frac{\delta y_{t-j}}{\delta x_{t}^{+}} \neq L_{h}^{-}=\sum_{j=0}^{h} \frac{\delta y_{t-j}}{\delta x_{t}^{-}} \neq 0
\end{array}
$$

Tablo1. Değişkenlerin Tanımlanması

\begin{tabular}{lll}
\hline DEĞiş̧KEN & KISALTMA & BİRIM \\
\hline Milli Gelir & LMG & (TL)/2009 sabit fiyatlarıyla \\
\hline Eğitim Harcamaları & LEH & (TL) \\
\hline
\end{tabular}

Kaynak: (OECD 2021), (Hazine ve Maliye Bakanlı̆̆ 2021). 
$\mathrm{LMG}=\beta_{0}+\beta_{1} \mathrm{LEH}+\mathrm{u}_{\mathrm{t}}$

Çalışmada logaritmik forma dönüştürülen değişkenler milli gelir bağımlı değişken, eğitim harcamaları ise bağımsız değişken olacak şekilde analiz yapılmaktadır. Ayrıca, çalışmada kullanılan değişkenler Tablo 1' de yer almaktadır. (6) numaralı denklemde, milli gelir "LMG", eğitim harcamaları "EH" ile temsil edilmektedir. Burada $\beta_{0}$ modelin sabit terimini ve $u_{t}$ hata terimini ifade etmektedir. Denklemin sağ tarafında logaritması alınmış LEH (Eğitim harcamaları) bağımsız değişkeni ve bu değişkene ait parametre $\beta_{1}$ yer almaktadır. Ayrıca, LMG ve LEH değişkenleri trend etkisinden arındırılarak modele dahil edilmektedir.

\subsection{Birim Kök Testi Sonuçları}

Çalışmada birim kök testlerinden literatürde en çok tercih edilen Augmented Dickey Fuller (ADF) ve Phillips Perron (PP) testleri uygulanmaktadır. Birim kök testi sonuçlarından elde edilen bulgulara göre serilerin I(0) ve I(1) olmak üzere farklı derecelerde bütünleşen oldukları görülmektedir (Bknz: Tablo 2).

Tablo 2. Birim Kök Testi Sonuçları

\begin{tabular}{ccccc}
\hline Değişkenler & $\begin{array}{c}\text { Birim Kök } \\
\text { Testi }\end{array}$ & $\begin{array}{c}\text { Düzey } \\
\text { (Sabit Terim) }\end{array}$ & $\begin{array}{c}\text { Birinci Fark } \\
\text { (Sabit Terim) }\end{array}$ & Sonuç \\
\hline LEH & ADF & -5.714919 & -5.62828 & $\mathrm{I}(0)$ \\
& & $(-2.63473)^{*}$ & $(-3.63940)^{*}$ & \\
LMG & ADF & -1.82513 & -5.35070 & $\mathrm{I}(1)$ \\
& & $(-3.66166)$ & $(-2.63473)^{*}$ & \\
LEH & PP & -1.56079 & -5.71491 & $\mathrm{I}(1)$ \\
& & $(-3.63290)$ & $(-2.63473)^{*}$ & \\
LMG & PP & -1.705327 & -7.54966 & $\mathrm{I}(1)$ \\
& & $(-3.63290)$ & $(-3.63940)^{*}$ & \\
\hline
\end{tabular}

Not: *, **,*** simgeleri sırasıyla $\% 1, \% 5$ ve $\% 10$ anlamlılık düzeylerini göstermektedir. Parantez içindeki ifadeler olasıllk değerlerini ifade etmektedir.

$\mathrm{Bu}$ nedenle literatürde yer alan diğer eş-bütünleşme testlerinin aynı durağanlık şartı kısıtlayıcı faktörünü ortadan kaldıran ve farklı durağanlık düzeylerinde eş bütünleşme ilişkisinin araştırılmasına olanak sağlayan ARDL sınır testi yaklaşımı modelimiz açısından uygun görülmektedir.

\subsection{ARDL Modeli Tahmin Sonuçlart}

I(0) ve I(1) olmak üzere farklı durağanlaşma düzeylerine sahip olan zaman serilere uygulanan ARDL modeli tahmin Sonuçları Tablo 3'de yer almaktadır. Oluşturulan modelde ARDL sınır testi yaklaşımına göre 3.70961 olan F istatistik değeri tablo alt ve üst kritik değerleri ile kıyaslandığında \%1, \%5 anlam düzeyinde sınırın altında, \%10 anlam düzeyinde ise alt ve üst kritik değerin arasında kararsız bölgede yer almaktadır. 
Tablo 3. ARDL Modeli Tahmin Sonuçları

\begin{tabular}{lllcc}
\hline $\begin{array}{l}\text { Bağımlı Değişken } \\
\text { Bağımsız } \\
\text { Değişken }\end{array}$ & Katsayı & $\begin{array}{l}\text { Standart } \\
\text { Hata }\end{array}$ & $\begin{array}{r}\text { ARDL(2,0) } \\
\text { t istatistiği }\end{array}$ & $\begin{array}{c}\text { Olasılık } \\
\text { Değeri }\end{array}$ \\
\hline C & -0.0425859 & 0.081556 & -0.522167 & 0.605 \\
LMG(-1) & 0.3375909 & 0.1732853 & 1.948179 & 0.060 \\
LMG(-2) & 0.221022 & 0.156481 & 1.412453 & 0.168 \\
LEH & 0.641547 & 0.3123082 & 2.0542121 & 0.048 \\
R-squared & 0.48728 & & Prob(F-statistic) & 0.000143 \\
Adjusted R- Squared & 0.43601 & & Akaike info criterion & 1.439280 \\
F-statistic & 9.50401 & Durbin-Watson stat & 2.090734 \\
\hline
\end{tabular}

Not: Modelde değişkenlere ait katsayıların yanında belirtilen $*, * *, * * *$ sırasıyla $\% 1, \% 5$ ve $\% 10$ anlam düzeylerini ifade etmektedir. Sınır testi yaklaşımına göre, model için F-istatistik değerinin 3.70961 olduğu görülmektedir. Sınır testi alt kritik değerlerinin sirasıyla $\% 1, \% 5$ ve \%10 anlam düzeylerinde: (5.76), (3.95), (3.22) ve üst kritik değerlerinin sırasıyla $\% 1, \% 5$ ve $\% 10$ anlam düzeylerinde: (6.48), (4.53), (3.75) olduğu görülmektedir.

$\mathrm{Bu}$ durum, seride eş-bütünleşme yoktur şeklinde kurulan $\mathrm{H}_{0}$ hipotezinin reddedilmesine imkân vermemektedir. Dolayısıyla bu sonuç, seride bir asimetri ilişkisinin varlığına işaret etmektedir.

\subsection{NARDL Tahmin Sonuçlart}

Modeldeki seriler arasında Eş-bütünleşme olup olmadığının tespiti için AECM kurulmaktadır. Çalışmada kullanılan modele göre oluşturulan AECM (3.4.1) numaralı denklemi şeklinde ifade edilmektedir.

$$
\begin{gathered}
E H_{t}^{+}=\sum_{j=1}^{t} \Delta E H_{t}^{+}=\sum_{j=1}^{t} \max \left(\Delta E H_{j}^{t}, 0\right) ; \\
E H_{t}^{-}=\sum_{j=1}^{t} \Delta E H_{t}^{-}=\sum_{j=1}^{t} \max \left(\Delta E H_{j}^{t}, 0\right)
\end{gathered}
$$

Model için asimetrik ilişkinin bulunduğu değişken için oluşturulan denklem (7), modelde kısa ve uzun dönemde asimetrik ilişkinin varlığını ortaya koymaktadır (Utkulu ve Ekinci 2015, 7-10).

$$
\Delta M G=\beta_{0}+\beta_{1} \ln E H_{t-1}+\sum_{i=0}^{p-1} \beta_{2} \Delta \ln M G_{t-1}+\pi_{1}^{+} \sum_{j=0}^{q} \Delta \ln E H_{t-i}^{+}+\pi_{1}^{-} \sum_{j=0}^{q} \Delta \ln E H_{t-i}^{-}+\varepsilon_{t}
$$

Denklemde yer alan + ve - üst simgeler ayrıştırma metoduyla elde edilen pozitif negatif kısmi toplamları ifade etmektedir. Ayrıca $\beta_{0}$ modelin sabit terimini, $\Delta$ birinci fark işlemcisini ve $e_{t}$ hata terimini ifade etmektedir.

$$
\begin{aligned}
& \mathrm{H}_{0}: \beta_{1}=\beta_{2}=\pi_{1}^{+}=\pi_{1}^{-}=0 \text { (Eş-bütünleşme yoktur) } \\
& \mathrm{H}_{1}: \beta_{1} \neq \beta_{2} \neq \pi_{1}^{+} \neq \pi_{1}^{-} \neq 0 \text { (Eş-bütünleşme vardır) }
\end{aligned}
$$


Modele ait $\mathrm{F}$ değerini ( $\left.\mathrm{F}_{\mathrm{W}}\right)$, Pesaran vd. (2001) tarafından geliştirilen $\mathrm{I}(0)$ alt kritik $\left(\mathrm{F}_{\mathrm{p}}{ }^{\mathrm{a}}\right)$ ve $\mathrm{I}(1)$ üst kritik $\left(\mathrm{F}_{\mathrm{p}}{ }^{\mathrm{u}}\right)$ değerleri ile karşılaştırdığımızda $\mathrm{F}_{\mathrm{W}}>\mathrm{F}_{\mathrm{p}}{ }^{\mathrm{u}}$ olduğu görülmekte ve $\mathrm{H}_{0}$ hipotezi reddedilmektedir. Böylece, seriler arasında eş-bütünleşmenin varlığı tespit edilmektedir. Yukarıdaki modellerde ifade edilen uzun dönemli ortak bütünleme ilişkisi düzey (fark1 alınmamış) gecikmeli değişkenlerin istatistiksel anlamlılığına bağlıdır. Dolayısıyla test bu katsayıların sıfıra eşit oldukları varsayımı altında yapılmaktadır.

Pesaran vd. (2001)'e göre yapılan sınır testinde model için oluşturulan (8) numaralı denklem birinci kısım uzun dönemli ilişki katsayılarını vermektedir. İkinci kısım ise asimetrik etkileri içeren değişkenlerin gecikmelerini içermektedir. Buradaki değişkenler, kısa dönemli asimetrinin hem güçlü hem de zayıf formda test edilmesinde kullanılmaktadır. Güçlü formdaki kısa dönemli asimetri, gecikmeli değerlere sahip pozitif asimetrileri ve negatif asimetrileri ifade eden katsayıların eşit olduğu durumda $\left(\pi_{1}^{+}=\pi_{1}^{-}\right), \mathrm{H}_{0}$ hipotezinin test edilmesiyle araştırılmaktadır. Burada boş hipotez eğitim harcamaları için:

$$
\begin{aligned}
& H_{0}: \sum_{i=0}^{p} \pi_{1}^{+}=\sum_{i=0}^{p} \pi_{1}^{-}=0 \\
& H_{1}: \sum_{i=0}^{p} \pi_{1}^{+} \neq \sum_{i=0}^{p} \pi_{1}^{-} \neq 0 \text { şeklindedir. }
\end{aligned}
$$

NARDL modelinde Milli gelir üzerinde asimetrik dinamik çarpan etkileri, yani uzun dönem katsayılarının ( $\mathrm{L}_{\mathrm{h}}^{+}$ve $\mathrm{L}_{\mathrm{h}}^{-}$) birbirine eşit olduğu boş hipotez test edilmektedir:

$$
\begin{aligned}
& H_{0}: L_{h}^{+}=\sum_{j=0}^{h} \frac{\delta M G_{t-1}}{\delta E H_{t}^{+}}=L_{h}^{-}=\sum_{j=0}^{h} \frac{\delta M G_{t-1}}{\delta E H_{t}^{-}}=0 \\
& H_{1}: L_{h}^{+}=\sum_{j=0}^{h} \frac{\delta M G_{t-1}}{\delta E H_{t}^{+}} \neq L_{h}^{-}=\sum_{j=0}^{h} \frac{\delta M G_{t-1}}{\delta E H_{t}^{-}} \neq 0
\end{aligned}
$$

Uygulanan NARDL yöntemine ilişkin tahmin sonuçları Tablo 4'te yer almaktadır. Oluşturulan modelde NARDL sınır testi yaklaşımına göre 4.34873 olan F-istatistik değeri tablo alt ve üst kritik değerleri ile kıyaslandığında \%5 ve \%10 anlam düzeylerinde ve tablo üst kritik değerinin üzerinde yer almaktadır. $\mathrm{Bu}$ durum, eş-bütünleşme yoktur şeklinde kurulan $\mathrm{H}_{0}$ hipotezinin reddedilmesine neden olmaktadır. Böylece, kabul edilen $\mathrm{H}_{1}$ hipotezi ile seriler arasında eş-bütünleşme ilişsisinin olduğu sonucuna ulaşılmaktadır. Uzun dönem ve kısa dönem katsayıları model kapsamında tahmin edilmektedir. 
Tablo 4. NARDL Modeli Tahmin Sonuçları

\begin{tabular}{|c|c|c|c|c|}
\hline \multirow{2}{*}{$\begin{array}{c}\text { Bağımlı Değişken } \\
\\
\text { Bağımsız } \\
\text { Değișken }\end{array}$} & \multicolumn{4}{|c|}{ NARDL(1,0,2) } \\
\hline & Katsayı & Standart Hata & $\mathbf{t}$ istatistiğ $\mathbf{i}$ & $\begin{array}{l}\text { Olasılık } \\
\text { Değeri }\end{array}$ \\
\hline $\mathrm{c}$ & 0.151469 & 0.3712782 & 0.407967 & 0.686 \\
\hline LMG(-1) & 0.1516357 & 0.206127 & 0.735642 & 0.468 \\
\hline$\left(\mathrm{LEH}^{+}\right)$ & $1.297652 * *$ & 0.4413328 & 2.940304 & 0.006 \\
\hline$\left(\mathrm{L}_{\mathrm{EH}}^{-}\right)$ & -0.703609 & 0.866579 & -0.811939 & 0.423 \\
\hline $\mathrm{D}\left(\mathrm{L}_{\mathrm{EH}}^{-}\right)(-1)$ & 0.4243686 & 1.115222 & 0.380523 & 0.706 \\
\hline $\mathrm{D}\left(\mathrm{L}_{\mathrm{EH}}{ }^{-}\right)(-2)$ & 1.3027527 & 0.833606 & 1.562791 & 0.129 \\
\hline R-squared & 0.518748 & & $\begin{array}{c}\text { Prob } \\
\text { (F-statistic) }\end{array}$ & 0.0009010 \\
\hline $\begin{array}{l}\text { Adjusted R- } \\
\text { Squared }\end{array}$ & 0.429627 & & Akaike info criterion & 1.492385 \\
\hline F-statistic & 5.8207429 & & Durbin-Watson stat & 1.791808 \\
\hline
\end{tabular}

Not: Modelde değişkenlere ait katsayıların yanında belirtilen $*, * *, * * *$ sırasıyla $\% 1, \% 5$ ve $\% 10$ anlam düzeylerini ifade etmektedir. Sınır testi yaklaşımına göre, model için F-istatistik değerinin 4.34873 olduğu görülmektedir. Sınır testi alt kritik değerlerinin sırasıyla \%1, \%5 ve \%10 anlam düzeylerinde: (4.94), (3.47), (2.84) ve üst kritik değerlerinin sirasıyla \%1, \%5 ve \%10 anlam düzeylerinde: (6.02), (4.33), (3.62) olduğu görülmektedir.

\subsection{NARDL Uzun ve Kısa Dönem Tahmin Sonuçları}

Tablo 5'te yer alan NARDL modeline ilişkin uzun ve kısa dönem tahmin sonuçları incelendiğinde, uzun dönemde eğitim harcamalarındaki pozitif $\left(\mathrm{LEH}^{+}\right)$etkinin istatistiksel olarak anlamlı ve pozitif katsayıya sahip olduğu görülmektedir. Uzun dönemde $\left(\mathrm{LEH}^{+}\right)$eğitim harcamaları katsayısı 1.297652 ve eğitim harcamalarındaki yüzde 1'lik artış milli gelirde yüzde 1.297'lik bir artışa yol açmaktadır. Böylece, incelenen dönemde Türkiye'de eğitim harcamalarındaki pozitif şoklara (artışlara) milli gelirin artarak tepki verdiği görülmektedir.

Şekil 1'de, milli gelir yaklaşık 1.5 dönem sonra uzun dönem durağan durumuna ulaşmaktadır. Durağan durum denge noktasına kadar milli gelir, hem $\left(\mathrm{LEH}^{+}\right)$pozitif şoklara hem de $\left(\mathrm{LEH}^{-}\right)$negatif şoklara göre artarak tepki vermekte ve $\left(\mathrm{LEH}^{+}\right)$pozitif şoklar milli geliri, negatif şoklara göre daha fazla arttırmaktadır. Durağan durumdan sonra ise, $\left(\mathrm{LEH}^{+}\right)$negatif şokların milli gelir üzerindeki etkisinin daha büyük olduğu görülmektedir. 


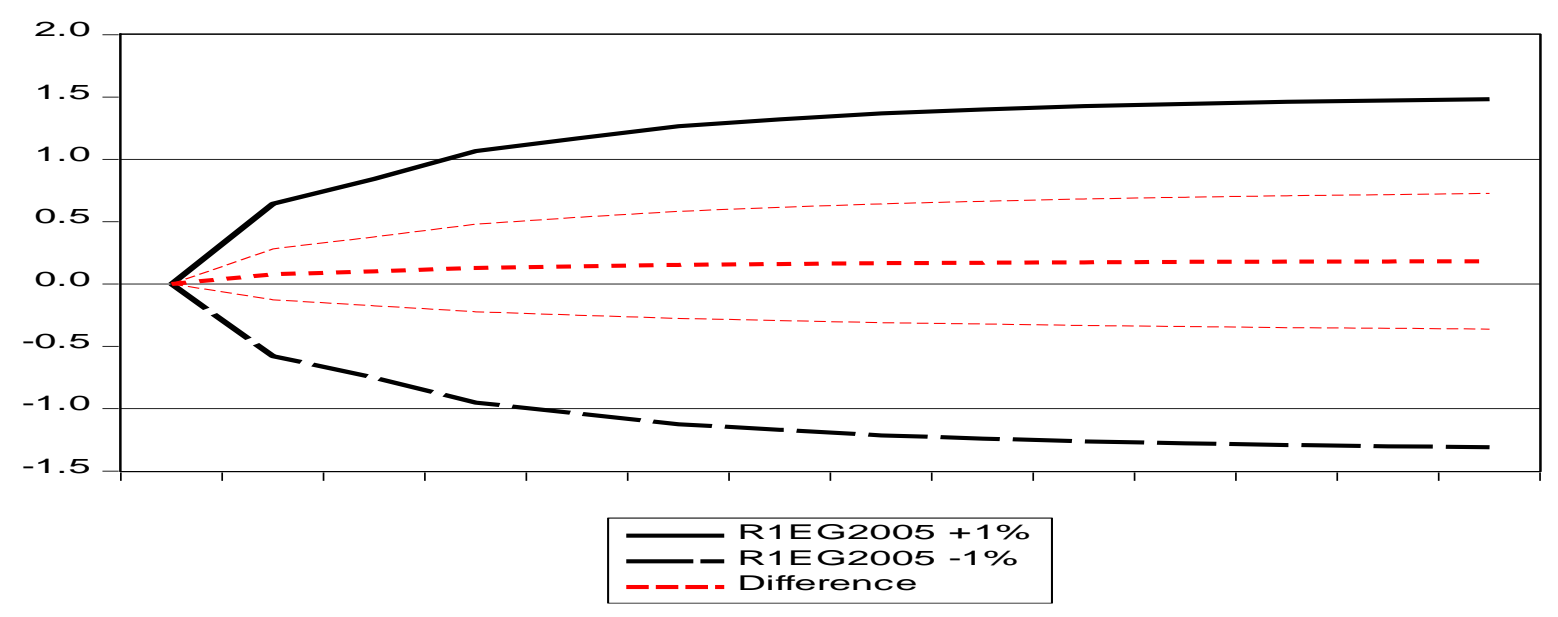

Şekil 1.Eğitim Harcamalarından Milli Gelire Doğru Birikimli Asimetrik Uzun Dönem Etki Tepki Fonksiyonu

Tablo 5. NARDL Uzun ve K1sa Dönem Tahmin Sonuçları

\begin{tabular}{ccccc}
\hline $\begin{array}{c}\text { Bağımlı } \\
\text { Değişken }\end{array}$ & \multicolumn{3}{c}{ NARDL(1,0,2) Uzun Dönem Tahmin Sonuçları } \\
$\begin{array}{c}\text { Bağımsız } \\
\text { Değişken }\end{array}$ & Katsayı & $\begin{array}{c}\text { Standart } \\
\text { Hata }\end{array}$ & t istatistiği & $\begin{array}{c}\text { Olasılık } \\
\text { Değeri }\end{array}$ \\
\hline $\mathrm{c}$ & 0.1514694 & 0.371278 & 0.407967 & 0.686 \\
$\mathrm{MG}(-1)$ & $-0.848364^{* *}$ & 0.206127 & -4.115735 & 0.0003 \\
$\left(\mathrm{~L}_{\mathrm{EH}}{ }^{+}\right)$ & $1.297652^{* *}$ & 0.441332 & 2.940304 & 0.006 \\
$\left(\mathrm{~L}_{\mathrm{EH}}^{-}\right)(-1)$ & 1.0235114 & 0.4049005 & 2.527809 & 0.017 \\
$\mathrm{D}\left(\mathrm{L}_{\mathrm{EH}}{ }^{-}\right)$ & -0.703609 & 0.866579 & -0.811939 & 0.423 \\
$\mathrm{D}\left(\mathrm{L}_{\mathrm{EH}}\right)(-1)$ & -1.3027527 & 0.833606 & -1.562791 & 0.129 \\
\hline & $\mathbf{N A R D L}(\mathbf{1 , 0 , 2})$ Kısa Dönem Tahmin Sonuçları & \\
\hline $\mathrm{c}$ & 0.1785429 & 0.441079 & 0.404786 & 0.688 \\
$\left(\mathrm{~L}_{\mathrm{EH}}{ }^{+}\right)$ & $1.529593^{* *}$ & 0.378911 & 4.036805 & 0.0004 \\
$\left(\mathrm{~L}_{\mathrm{EH}}^{-}\right)$ & $1.206452^{* *}$ & 0.398137 & 3.030238 & 0.005 \\
Uyum katsayısı & $-0.4487505^{* *}$ & 0.126946 & -3.534947 & 0.001 \\
\hline
\end{tabular}

Not: Modeldeki değişkenlere ait katsayıların yanında belirtilen ***,*** sırasıyla $\% 1, \% 5, \% 10$ anlam düzeylerini ifade etmektedir.

Kısa dönem tahmin sonuçları incelediğinde, modelde hem pozitif $\left(\mathrm{LEH}^{+}\right)$şokların hem de negatif $\left(\mathrm{LEH}^{-}\right)$şokların \% 5 anlam düzeyinde istatistiki olarak anlamlı olduğu görülmektedir. Pozitif $\left(\mathrm{LEH}^{+}\right)$etki uzun döneme paralel bir şekilde pozitif katsayıya sahip iken, negatif $\left(\mathrm{LEH}^{-}\right.$ ) etki uzun dönemden farklı olarak pozitif bir katsayı ile ortaya çıkmaktadır. Kısa dönemde $\left(\mathrm{LEH}^{+}\right)$katsayısı 1.529593 ve eğitim harcamalarındaki yüzde 1'lik artış milli gelirde yüzde 1.52'lik artışa neden olur iken, $\left(\mathrm{LEH}^{-}\right)$etkinin 1.20645 katsayısı ile eğitim harcamalarındaki yüzde \%1'lik artışın milli gelirde yüzde 1.20'lik bir azalışa yol açtığı görülmektedir. Böylece incelenen dönemde, Türkiye' de eğitim harcamalarındaki pozitif şoklara milli gelir artarak tepki verir iken, negatif şoklara azalarak tepki vermektedir. Kısa dönemde uyum katsayı 
incelendiğinde, bu katsayının \%1 anlam düzeyinde anlamlı olduğu ve kısa dönemde uzun dönem dengesinden sapma olduğunda, sistemin dengeye gelmesinin yaklaşık 1.5 çeyrek dönemde gerçekleşeceği sonucuna ulaşılmaktadır.

\section{Sonuç}

Eğitim, ülkelerin sosyal ve iktisadi gelişmelerine katk1 sağlayarak küresel rekabet gücü yaratan önemli bir faktördür. Bu bakımdan büyüme ve kalkınma için geliştirilecek politikaların içinde eğitim politikalarına atfedilecek önemin belirlenmesi gerekmektedir. Bu nedenle, Türkiye'de eğitimin büyüme üzerindeki etkisinin araştırılması amacını taşıyan bu çalışmada, NARDL sınır testi yaklaşımından elde edilen bulgular neticesinde: Türkiye'de 1980-2015 dönemine ait milli gelir, hem kısa hem uzun dönemde, eğitim harcamalarındaki pozitif $\left(\mathrm{LEH}^{+}\right)$şoklara artarak tepki vermektedir. Negatif $\left(\mathrm{LEH}^{-}\right)$şoklar ise sadece kısa dönemde $\% 5$ anlam düzeyinde istatistiksel olarak anlamlıdır ve milli gelir aleyhine bir durum sergilemektedir. Ampirik bulgular incelendiğinde, pozitif $\left(\mathrm{LEH}^{+}\right)$şoklara ait katsayıların 1'den büyük değer aldığı ortaya çıkmaktadır. Ayrıca iktisadi açıdan bu değer, yarı kamu mal olan eğitimin, kamu hizmetleri içerisinde lüks mal sınıfında değerlendirilmesine olanak sağlamakta ve eğitimin büyüme üzerinde pozitif dışsallık yarattığı doğrulanmaktadır. Bu sonuç, literatürdeki diğer çalışmaların eğitim harcamalarının ekonomik büyümeyi olumlu etkilediği sonucu ile benzerlik göstermektedir. Ancak bu çalışmada diğer çalışmaların aksine eğitim harcamalarındaki azalmanın, yani eğitim harcamalarındaki negatif şokların da etkisi incelenmektedir. Eğitim harcamalarında negatif şoklar, kısa dönemde ekonomik büyüme aleyhine bir sonuç yaratmaktadır. $\mathrm{Bu}$ çalışmada, NARDL modelinin asimetrik yönünün incelenmesine imkân sağlayan pozitif ve negatif şok ayırımı sayesinde, literatürdeki diğer doğrusal model çalışmalarının aksine, sadece artışın değil azalışın da etkisi gösterilmektedir.

Elde edilen sonuçlar, eğitim harcamalarındaki artışın, büyümeyi hem kısa dönem hem de uzun dönemde olumlu etkilediğini ve eğitime yapılan yatırımların fiziksel sermaye yatırımları kadar önem taşıdığını göstermektedir. Ayrıca, diğer bir sonuç olarak ortaya çıkan durum, eğitim harcamalarındaki azalışın ekonomik büyüme üzerindeki olumsuz etkisi, bu çıkarımı destekler niteliktedir. Nitekim, beşerî sermaye oluşumunun temel koşulu olarak eğitim, nitelikli işgücünün artmasına neden olmakta ve üretimin, dolayısıyla gelirin artmasına katkı sağlamaktadır. Kamu hizmetleri kapsamında gerçekleştirilen eğitim hizmetleri devlet eliyle gerçekleştirildiğinde firsat eşitliğini de yaratmaktadır. $\mathrm{Bu}$ nedenle, büyüme stratejileri belirlenirken eğitime ayrılan payın arttırılmasının, pozitif dışsallık etkisi nedeniyle geliri 
Yürük, B., Acaroğlu, H. / Journal of Yasar University, 2021, 16/61, 1301-1317

beklendiğinden daha fazla arttırması, büyüme için nitelikli eğitime önem verilmesini gerekli kilmaktadir. 


\section{KAYNAKLAR}

Afşar, M. 2009. “Türkiye’de Eğitim Yatırımları ve Ekonomik Büyüme İlişkisi.” Anadolu Üniversitesi Sosyal Bilimler Dergisi 9(1): 85-98.

Afzal, M., \& Qaisar A. 2010. “Wagner's law in Pakistan: Another look.” Journal of Economics and International Finance 2(1): 012-019.

Akçacı, T. 2013. “Eğitim Harcamalarının İktisadi Büyümeye Etkisi.” Kafkas Üniversitesi İktisadi ve İdari Bilimler Fakültesi Dergisi 4(5): 65-79.

Akını, A. 2017. “Türkiye'de Eğitim Harcamalarının Ekonomik Büyüme Üzerindeki Etkisi.” Maliye Dergisi 173 : 387-397

Arabacı, İ.B. 2011. Türkiye’ de ve OECD Ülkelerinde Eğitim Harcamaları. Elektronik Sosyal Bilimler Dergisi 10(35): 100-112.

Barro, R. J. 1991. "Economic Growth in a Cross Section of Countries." The Quar terly Journal of Economics 106(2): 407-443.

Becker, G. 1964. Human capital: A Theoretical and Empirical Analysis with Special Reference to Education. Columbia University Press, New York.

Bird, R. M. 1971. "Wagner's "Law” of Expanding State Activity." Public Finance 26, 1-26.

Çoban, O. 2004. "Beşeri Sermayenin İktisadi Büyüme Üzerindeki Etkisi: Türkiye Örneği.” İstanbul Üniversitesi S.B.F. Dergisi 30: 131-142.

Denıson, E. F. 1985. “Trends in American Economic Growth, 1929-1982.” American Journal of Agricultural Economics 68(3): 751-752.

Denison, E. F. 1962. "Education, Economic Growth, and Gaps in Information." Journal of Political Economy 70(5): 124-128.

Devrim, F. ve Tosuner M. 1987. “Türkiye'de Eğitim Hizmetlerinin Finansmanında Son Gelişmeler.” 3. Türkiye Maliye Eğitimi Sempozyumu Kitabı içinde (86-109). T.C. İstanbul Üniversitesi, İktisat Fakültesi, Maliye Bölümü, Kocaeli.

Edizdoğan, N., Çetinkaya, Ö. ve Gümüş E. 2012. Kamu Maliyesi. Bursa: Ekin Yayınevi.

Eriçok, R. E. ve Yılancı, V. 2013. "Eğitim Harcamaları ve Ekonomik Büyüme İlişkisi: Sınır Testi Yaklaşımı." Bilgi Ekonomisi ve Yönetimi Dergisi 8(1): 87-101

Granger, C. W. J. 1969. "Investigating Causal Relations by Econometric Models and Cross- Spectral Methods." Econometrica 37(3): 424-438. https://doi.org/10.2307/1912791

Granger, C. W., \& Yoon, G. 2002. "Hidden cointegration.” U of California, Economics Working Paper $2002-02$. https://escholarship.org/uc/item/9qn5f61j

Harbison, F. H. 1971. "Human Resources as the Wealth of Nations." American Philosophical Society 115(6): 426431.

Hazine ve Maliye Bakanlığı. Erişim Tarihi: 30.01.2021 https://www.hazine.gov.tr/hazine-mustesarligi-veridagitim-sistemi

Hussin, M. Y. M., Muhammad, F., Hussin, M. F. A., \& Razak, A. A. 2012. "Education Expenditure and Economic Growth: A Causal Analysis for Malaysia." Journal of Economics and Sustainable Development 3(7): 7181.

Idrees, A. S., \& Siddiqi, M. W. 2013. "Does Public Education Expenditure Cause Economic Growth? Comparison of Developed and Developing Countries." Pakistan Journal of Commerce and Social Sciences (PJCSS) 7(1): 174-183

İğdeli, A. 2019. “Ar-Ge ve Eğitim Harcamalarının Ekonomik Büyüme Üzerindeki Etkisi: Türkiye Örneği.” Manas Sosyal Araştırmalar Dergisi 8(3): 2517-2538.

Karataş, M. ve Çankaya, E. 2011. "Türkiye'de Beşeri Sermaye ve Ekonomik Büyüme İlişkisinin Analizi." Yönetim ve Ekonomi Dergisi 18(1): 105-214.

Karış, Ç. 2019. "Eğitim Harcamaları ve Ekonomik Büyüme Üzerine Bir Nedensellik Analizi: Türkiye Örneği." Bingöl Üniversitesi Sosyal Bilimler Enstitüsü Dergisi 9(18): 1067-1088.

Kızılkaya, O., ve Koçak, E. 2014. "Kamu Eğitim Harcamaları ve Ekonomik Büyüme İlişkisi: Seçilmiş OECD Ülkeleri Üzerine Bir Panel Veri Analizi.” Ekonomi Bilimleri Dergisi 6(1): 17-32.

Lucas, R. E. 1988. “On the Mechanics of Economic Development.” Journal of Monetary Economics 22 (1): 3-42.

Mallick, L., \& Dash, D. P. 2015. "Does Expenditure on Education Affect Economic Growth in India? Evidence From Cointegration and Granger Causality Analysis." Theoretical \& Applied Economics 22(4):63-74.

Mankiw, N. G., Romer, D. \& Weil, D. N. 1992. "A Contribution to the Empirics of Economic Growth." The Quarterly Journal of Economics 107(2): 407-437.

Mincer, J. 1973. "Investment in Human Capital and Personal Income Distribution. ” Journal of Political Economy 116(4): 281-302.

Musila, J.W. \& Belassi, W. 2004. "The impact of Education Expenditures on Economic Growth in Uganda: Evidence From time Series Data." The Journal of Developing Areas 38(1): 123-133.

OECD. “OECD Statistics” Erişim Tarihi: 30.01.2021. https://stats.oecd.org/ 
Oktayer, A. 2011. "Türkiye'de Ekonomik Büyüme Ve Kamu Harcamaları Arasındaki İlişkinin Ampirik Analizi: 1950-2009." İstanbul Üniversitesi İktisat Fakültesi Mecmuası 61(1): 261-282.

Özsoy, C. 2009. "Türkiye'de Eğitim ve İktisadi Büyüme Arasındaki İlişkinin VAR Modeli ile Analizi.” Bilgi Ekonomisi ve Yönetimi Dergisi 4(1): 71-83.

Öztürk, A. Kalaycı, S., ve Korkmaz, N. 2017.’Türkiyede Eğitim Harcamalarının İktisadi Büyümeye Etkisi: Ekonometrik Bir Analiz.” Mehmet Akif Ersoy Ĕ̈itim Bilimleri Enstitüsü Dergisi 5(7): 17-29.

Pamuk, M., ve Bektaş, H. 2014. “Türkiye'de Eğitim Harcamaları ve Ekonomik Büyüme Arasındaki İlişki: ARDL Sınır Testi Yaklaşımı." Siyaset, Ekonomi ve Yönetim Araştırmaları Dergisi 2(2):77-90.

Pesaran, M., Shin, Y. \& Smith, R. J. 2001. "Bounds Testing Approaches to the Analysis of Level Relationships." Journal of Applied Econometrics 16: 289-326.

Pınar, A. (2006). Maliye politikası. Ankara: Natürel Yayınları.

Psacharopoulos, G. 1973. Returns to Education: An International Comparison. Amsterdam: Elsevier.

Psacharopoulos, G. 1994. "Returns to Investment in Education: A Global Update." World Development 22(9): 1325-1343.

Rebelo, S. 1991. "Long-Run Policy Analysis and Long-Run Growth.” The Journal of Political Economy 99 (3): 500-521.

Romer, P. M. 1986. "Increasing Returns and Long-Run Growth.” The Journal of Political Economy 94 (5): $1002-$ 1037.

Sarı, R., 2003. "Kamu Harcamalarının Dünyada ve Türkiye'deki Gelişimi ve Türkiye'de Ulusal Gelir ile İlişkisi." İktisat, Işletme ve Finans Dergisi 209: 25-38.

Schultz, T. W. 1961. "Investment in Human Capital." The American Economic Review 51(1): 1-17.

Schultz, T.W. 1967. Investment in Human Capital, Reading in Economics, Mc Graw-Hill.

Selim, S., Purtaş, Y., ve Uysal, D. 2014. "G-20 Ülkelerinde Eğitim Harcamalarının Ekonomik Büyüme Üzerindeki Etkisi.” Optimum Ekonomi ve Yönetim Bilimleri Dergisi 1(2):93-102.

Shin, Y., Yu, B. \& Greenwood-Nimmo, M. 2014. "Modelling Asymmetric Cointegration and Dynamic Multipliers in an ARDL Framework." Horrace, W.C. ve Sickles, R.C. (ed.), içinde, Econometric Methods and Applications (s.281-314), NewYork(NY): Festschrift in Honor of Peter Schmidt. Springer Science \& Business Media.

Solow, R. 1956. "A Contribution to the Theory of Economic Growth." The Quarterly Journal of Economics 70(1): 65-94.

Şimşek, T. 2017. “Türkiye'de Eğitim Harcaması ve Ekonomik Büyüme: ARDL Sınır Testi.” Enderun 1(1): 5460.

Toda, H. Y., \& Yamamoto, T., 1995. "Statistical Inference in Vector Autoregressions with Possibly Integrated Processes." Journal of Econometrics 66: 225-250. https://doi.org/10.1016/0304-4076(94)01616-8

Uçan, O. ve Yeşilyurt, H. 2016. “Türkiye'de Eğitim Harcamaları ve Büyüme İlişkisi.” Niğde Üniversitesi İktisadi ve Idari Bilimler Fakültesi Dergisi 9(2): 179-185.

Utkulu, U. ve Ekinci R. 2015. "Uluslararası Emtia Fiyatlarından İç Fiyatlara Asimetrik Ve Doğrusal Olmayan Fiyat Geçişkenliği: Türkiye İçin NARDL Modeli Bulguları.” Turkish Economic Association 53(617): 1022.

Yardımcıoğlu, F., Gürdal, T. ve Altundemir, M. E. 2014. "Education and Economic Growth: A panel Cointegration Approach in OECD Countries (1980-2008). Education and Science 39(173):1-12. 